\title{
Chromium in human milk from American mothers
}

\author{
By CLARE E. CASEY AND K. MICHAEL HAMBIDGE \\ Department of Pediatrics, University of Colorado Health Sciences Center, \\ Denver, Colorado 80262, USA
}

\section{(Received 25 October 1983 - Accepted 1 February 1984)}

\footnotetext{
1. The chromium concentration was determined in 261 samples of breast milk collected by manual expression from forty-five American women.

2. Cr was measured in whole, liquid milk by graphite-furnace atomic absorption spectrophotometry, using the method of standard additions.

3. The mean $\mathrm{Cr}$ content of the breast milk samples was $0.30 \mathrm{ng} / \mathrm{ml}$. The range of individual values was $0.06-1.56 \mathrm{ng} / \mathrm{ml}$ and did not change significantly with duration of lactation.

4. The Cr content of breast milk from these American women is similar to levels reported recently in milk from Finnish women.
}

Published values for the concentration of chromium in urine and blood have declined markedly over the past 20 years (Versieck \& Cornelis, 1980). This decline may be attributed mainly to improvements in analytical technology and to better recognition of the major problem of environmental contamination. A similar decline has occurred in reported levels for $\mathrm{Cr}$ in human milk. A range of $30-80 \mathrm{ng} / \mathrm{ml}$ was reported in the $1960 \mathrm{~s}$ for milk from Russian and Egyptian women (Medvedeva, 1966; Carter et al. 1968). In the 1970s, mean levels of 10-12 $\mathrm{ng} / \mathrm{ml}$ were reported for milk from American and New Zealand women (Hambidge, 1971; Casey, 1976). Recently, however, Kumpulainen \& Vuori (1980) found a mean level of Cr of only $0.39 \mathrm{ng} / \mathrm{ml}$ in milk from Finnish women. The diet of these Finnish mothers was lower in $\mathrm{Cr}$ than has been reported for populations from other parts of the world (Kumpulainen et al. 1980), and it was suggested that this may account, in part, for their low milk-Cr levels.

We have analysed the $\mathrm{Cr}$ content of human milk from American women, using graphite-furnace atomic absorption spectrophotometry and taking special care to minimize possible contamination at all stages of collection and analysis. We found a mean concentration of $\mathrm{Cr}$ of $0.30 \mathrm{ng} / \mathrm{ml}$, similar to the mean level reported recently in Finnish milk.

\section{MATERIALS AND METHODS \\ Collection of milk}

Milk was collected from a total of forty-five lactating women. All were healthy, well-nourished women living in the Denver area and were fully breast-feeding a healthy, full-term infant.

As this was part of a wider study of factors affecting milk composition, milk was collected at a variety of times. All mothers provided milk from both breasts and at least at mid-feed ( 2 min after let-down) in the mid-morning feed. Some mothers provided milk from other feeds in the day. Twenty women, of varying duration of lactation, collected fore-, mid- and hind-milk from both breasts at the mid-morning feed. The effect of duration of lactation was examined by grouping values for samples collected mid-feed (except colostrum), mid-morning, from the right breast. Two women were followed longitudinally from day of delivery to 12 weeks post-partum; all other results were cross-sectional, from 2 weeks pre-partum to 48 weeks post-partum. 
All individual milk samples were approximately $5 \mathrm{ml}$ and collected by manual expression into polystyrene vials. Before expressing milk, mothers rinsed the breast with deionized water and patted it dry with a cotton-gauze swab. Where necessary, an electric pump (Medela Inc., Crystal Lake, Illinois) was used to collect pre-colostrum and very early milk samples. (All parts of this pump in contact with milk are made of polyethylene and are removable for washing.) After thorough shaking, $0.5 \mathrm{ml}$ of the milk was taken for $\mathrm{Cr}$ analysis and stored in Eppendorf microcentrifuge tubes (Bio-rad Laboratories, Richmond, California) at $-70^{\circ}$.

\section{Analytical techniques}

Only plastic ware was used throughout. Except for breast pump parts all items were new and were pre-washed with detergent and thoroughly rinsed with $18 \mathrm{M} \Omega$ water (Milli-Q, Continental Water Systems, El Paso, Texas). Milk containers for the breast pump were re-used, and were washed each time by soaking for $24 \mathrm{~h}$ successively in detergent, $2 \mathrm{M}$-hydrochloric acid, $2 \mathrm{M}$-nitric acid and in deionized water twice, and rinsed between steps with deionized water. Fixed volume 'standard' Eppendorf pipettes (Brinkmann Instruments, Westbury, New York) were used with 'natural, metal-free' tips (Bio-rad Laboratories). Tips were rinsed with deionized water immediately prior to use.

$\mathrm{Cr}$ concentration was measured by the method of standard additions in liquid milk without pretreatment, using graphite-furnace atomic absorption spectrophotometry. Equipment used was the Perkin-Elmer 5000 atomic absorption spectrophotometer (Perkin-Elmer Corp., Norwalk, Connecticut) with the HGA 500 graphite furnace and PRS-10 printer. (The PE-5000 uses a tungsten halide continuum source to correct for background absorbance at the $\mathrm{Cr}$ wavelength.) The instrument settings were: $357.9 \mathrm{~nm} \mathrm{Cr} \mathrm{line,} 0.7 \mathrm{~nm}$ low slit width, peak height mode; read-out signal in concentration mode with $10 \times$ scale expansion and 7 s integration time. The autosampler was programmed to deliver $30 \mu \mathrm{l}$. Pyrolytically coated tubes were used in the graphite furnace, which was programmed as follows: step $1,110^{\circ}$ for $25 \mathrm{~s}$ ( $15 \mathrm{~s}$ ramp); step $2,130^{\circ}$ for $20 \mathrm{~s}$ (15 s ramp); step $3,1150^{\circ}$ for $60 \mathrm{~s}$ (15 s ramp); step $4,2700^{\circ}$ for $4 \mathrm{~s}\left(0 \mathrm{~s}\right.$ ramp); step $5,2700^{\circ}$ for $4 \mathrm{~s}$ ( $\left.1 \mathrm{~s} \mathrm{ramp}\right)$. Argon was used as the purge gas and the internal flow rate was reduced from $300 \mathrm{ml} / \mathrm{min}$ to $20 \mathrm{ml} / \mathrm{min}$ at the atomization step (step 4). The automatic baseline correction and start of integration time were programmed at $2 \mathrm{~s}$ and $1 \mathrm{~s}$ prior to atomization.

Working standards containing $\mathrm{Cr}$ concentrations of $0 \cdot 2-2 \cdot 0 \mathrm{ng} / \mathrm{ml}$ in $30 \mathrm{~mm}-\mathrm{HNO}_{3}$ were prepared weekly from a stock standard containing $1 \mathrm{mg} \mathrm{Cr} / 1$ (Baker Instra-Analyzed atomic spectral standard, J. T. Baker, Phillipsburg, New Jersey). The $30 \mathrm{~mm}-\mathrm{HNO}_{3}$ was prepared weekly from concentrated nitric acid (Baker Instra-analysed for trace metal analysis) and gave a blank reading below the limit of detection $(0.05 \mathrm{ng} \mathrm{Cr} / \mathrm{ml})$.

Milk samples were diluted for analysis as follows: $100 \mu 1$ of each of $30 \mathrm{~mm}-\mathrm{HNO}_{3}$ and three standard solutions containing $0.2,0.5$ and $0.8 \mathrm{ng} \mathrm{Cr} / \mathrm{ml}$ were pipetted into polystyrene autoanalyser cups (American Scientific Products, McGaw Park, Illinois). To each was added $10 \mu \mathrm{l}$ of an aqueous solution of $\mathrm{Mg}\left(\mathrm{NO}_{3}\right)_{2}$ containing $0.03 \mathrm{~g} / \mathrm{ml}$, as an ashing aid. The thawed milk was shaken vigorously by hand, $100 \mu \mathrm{l}$ was pipetted into each cup and the whole mixed by taking up and ejecting several times with the pipette. Each solution was analysed in quadruplicate. Mean peak height values were plotted against concentration of added $\mathrm{Cr}$ and the level in the milk was found by extrapolation of the line back to the horizontal axis.

A sample of pooled human milk was analysed with each set of milk samples and gave a day-to-day coefficient of variation of $7.9 \%$, mean 0.28 (SE 0.003$) \mathrm{ng} / \mathrm{ml}$. Recovery of added $\mathrm{Cr}$ was tested by adding standard solution to a larger volume of the pooled human milk and allowing this to stand at least overnight. The mean recovery was 103 (SE 1.8$) \%$. 


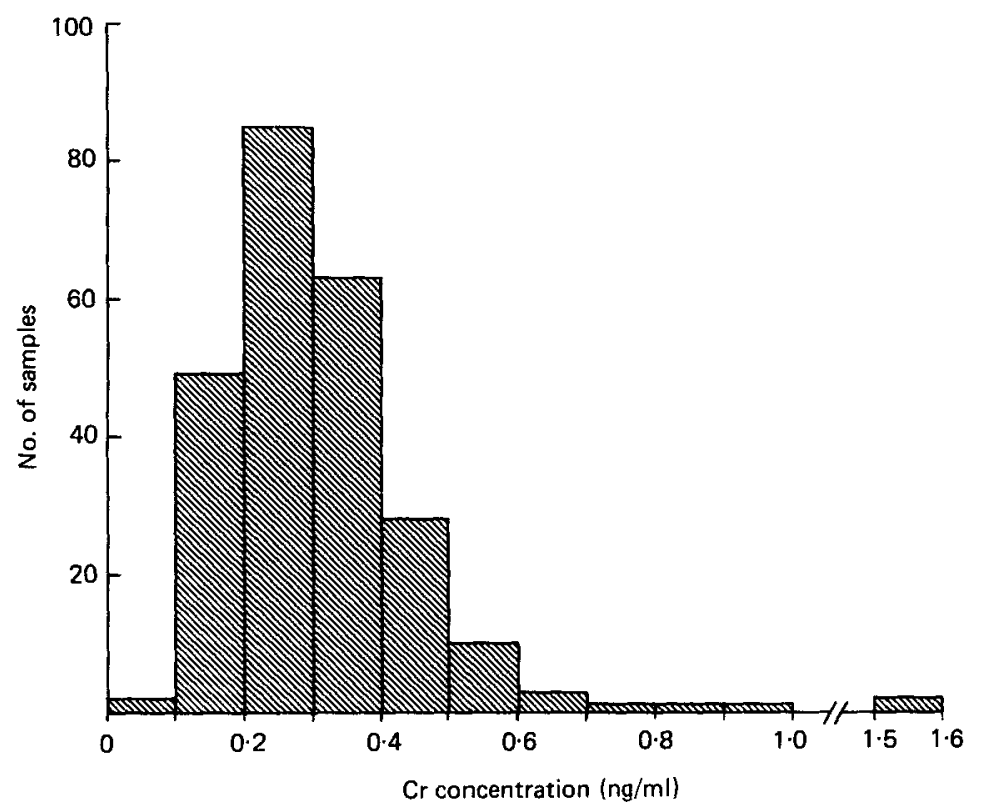

Fig. 1. Distribution frequencies of chromium content in human milk from American mothers. Mean $0.30 \mathrm{ng} / \mathrm{ml}$, median $0.27 \mathrm{ng} / \mathrm{ml}$.

In order to check the procedure for contamination, $30 \mathrm{~mm}-\mathrm{HNO}_{3}$ and milk from a large pooled sample were dripped into polystyrene vials, four of each, to mimic milk collection. Two $1 \mathrm{ml}$ portions were transferred to Eppendorf tubes from each vial; these were then frozen and later analysed as for the milk samples. $\mathrm{Cr}$ was below the limit of detection in the 'acid samples'; the mean concentration in the eight 'milk samples' was 0.26 (SD 0.03) $\mathrm{ng} / \mathrm{ml}$, and was not significantly different from the mean value found by analysis of thirteen milk samples taken directly from the pool $(0.27(\operatorname{SD} 0.03) \mathrm{ng} / \mathrm{ml})$. These results suggest that $\mathrm{Cr}$ contamination probably did not occur to any measurable extent on a consistent basis during collection and analysis of the breast milk samples.

There is no certified reference material for $\mathrm{Cr}$, with the appropriate matrix and at the low concentrations expected in milk, which could be used to test the accuracy of the method. However, the pooled human milk was analysed by isotope dilution mass spectrometry (Veillon et al. 1979) in Dr Claude Veillon's laboratory, USDA Human Nutrition Center, Beltsville, Maryland. Using this method, a concentration of 0.31 (SE 0.05 ) $\mathrm{ng} \mathrm{Cr} / \mathrm{ml}$ was found, in good agreement with the graphite-furnace result.

Two reference materials from the International Atomic Energy Agency (Vienna) were also analysed. Powdered milks A-11 (bovine) and HM-1 (human) were 'reconstituted' in deionized water with thorough shaking and mild heating. These 'liquid milks' were then analysed in the same manner as the study samples, giving values for $\mathrm{Cr}$ of: A-11, $19 \cdot 4$ (SE $1 \cdot 47) \mathrm{ng} / \mathrm{g}(n$ 6); HM-1, $9 \cdot 3$ (sE 0.04) $\mathrm{ng} / \mathrm{g}(n)$ ).

\section{RESULTS}

Cr was measured in a total of 255 milk samples from forty-five American women. Six individual results were rejected as being inconsistently higher than other values from the same mother on the same day, suggesting contamination of the samples. The over-all range 
Table 1. Concentrations of chromium $(\mathrm{ng} / \mathrm{ml})$ in breast milk from American mothers at various stages of lactation

\begin{tabular}{lcccccc}
\hline \hline & & \multicolumn{5}{c}{ Time after delivery } \\
& $\begin{array}{c}1-16 \mathrm{~d} \\
\text { pre-partum }\end{array}$ & $0-14 \mathrm{~d}$ & $15-28 \mathrm{~d}$ & $1-3$ months & $4-6$ months & $7+$ months \\
\hline Mean & 0.39 & 0.29 & 0.27 & 0.28 & 0.26 & 0.46 \\
SD & 0.23 & 0.09 & 0.13 & $0 \cdot 11$ & 0.12 & 0.41 \\
$n$ & 3 & 17 & 6 & 26 & 23 & 9 \\
\hline
\end{tabular}

of accepted values was $0.06-1.56 \mathrm{ng} / \mathrm{ml}$, with the majority of values being less than $0.4 \mathrm{ng} / \mathrm{ml}$. The frequency distribution of individual concentrations is shown in Fig. 1. The mean value for all 255 was $0.30(\mathrm{sD} 0.17) \mathrm{ng} / \mathrm{ml}$.

Analysis of variance of results from the twenty women who collected milk from both breasts at three times during one feed showed no significant effect due to time during feed or breast. The only significant variation was that between individuals $(F 4.376, P<0.001)$. Table 1 gives the mean values at each month of lactation. There was no significant effect of duration of lactation.

\section{DISCUSSION}

The average concentration of $\mathrm{Cr}$ in human milk found in the present study $(0.30 \mathrm{ng} / \mathrm{ml})$ is very similar to the mean value reported by Kumpulainen \& Vuori (1980) for milk from Finnish mothers $(0.39(\mathrm{sD} 0 \cdot 15) \mathrm{ng} / \mathrm{ml})$. These workers used a graphite-furnace technique after low-temperature ashing of the milk samples. They also found no effect due to duration of lactation. Thus results of the present study do not support the suggestion that Finnish mothers have a low level of $\mathrm{Cr}$ partly because of low dietary intake of $\mathrm{Cr}(30 \mu \mathrm{g} / \mathrm{d})$. We do not have values for dietary intakes of $\mathrm{Cr}$ by our group of mothers but levels reported elsewhere (Kumpulainen et al. 1979) indicate that the median intake in the USA is about $60 \mu \mathrm{g} / \mathrm{d}$.

The method reported here has the advantage of being more rapid than a technique requiring pretreatment and has fewer steps where contamination may be introduced. The small sample size $(400 \mu \mathrm{l})$ is also an advantage in a study where many milk constituents are being examined and large quantities of milk are not available.

The average amount of milk produced daily by our mothers at 1 month is $690 \mathrm{ml}$ (C. E. Casey and K. M. Hambidge, unpublished observations), giving a total daily output of $\mathrm{Cr}$ in the milk of $0.2 \mu \mathrm{g}$. The major route of excretion of endogenous $\mathrm{Cr}$ is in the urine; daily losses by healthy American women being in the order of $0.2 \mu \mathrm{g} / \mathrm{d}$ (Anderson et al. 1983). Thus the lactating mother will have, on average, a minimum daily loss of $0.4 \mu \mathrm{g} \mathrm{Cr}$. Cr absorption is low, less than $1 \%$ of the oral intake (Anderson et al. 1983). It is not known whether absorption increases in response to the greater demands of lactation, and further work is required before recommendations can be made about the optimum level of $\mathrm{Cr}$ intake during lactation.

The authors would like to thank the mothers for providing the milk and Mrs Joy Seacat for assistance in sample collection. This work was supported by contract no. 01 HD 22801 from the National Institutes of Health to Dr Margaret C. Neville, and Grant RR-69 from the National Institutes of Health, General Clinical Research Center. 


\section{REFERENCES}

Anderson, R. A., Polansky, M. M., Bryden, N. A., Patterson, K. Y., Veillon, C. \& Glinsmann, W. H. (1983). Journal of Nutrition 113, 276-281.

Carter, J. P., Katab, A., Abd-El-Hadi, K., Davis, J. T., El Gholmy, A. \& Patwardhan, V. N. (1968). American Journal of Clinical Nutrition 21, 195-202.

Casey, C. E. (1976). Proceedings of the University of Otago Medical School 54, 7-8.

Hambidge, K. M. (1971). In Newer Trace Elements in Nutrition, pp. 169-194, [W. Mertz and W. E. Cornatzer, editors]. New York: Marcel Dekker.

Kumpulainen, J. T. \& Vuori, E. (1980). American Journal of Clinical Nutrition 33, 2299-2302.

Kumpulainen, J. T., Vuori, E., Makinen, S. \& Kara, R. (1980). British Journal of Nutrition 44, 257-263.

Kumpulainen, J. T., Wolf, W. R., Veillon, C. \& Mertz, W. (1979). Journal of Agricultural and Food Chemistry 27, 490-494.

Medvedeva, V. I. (1966). Doklady Akademii Nauk Belorusskaia SSR 10, 98-100. Cited: Chemical Abstracts 64, 20316.

Veillon, C., Wolf, W. R. \& Guthrie, B. E. (1979). Analytical Chemistry 51, 1022-1024.

Versieck, J. \& Cornelis, R. (1980). Analytica Chimica Acta 116, 217-254. 